
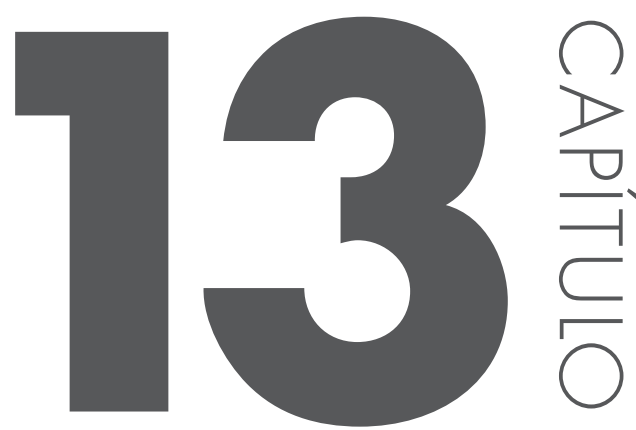

\title{
SETOR SUCROENERGÉTICO E TRANSFORMAC̣ÕES ESPACIAIS EM FRUTAL (MG)
}

Oliveira, Elvisley Rodrigues de ${ }^{1 *}$; Mendes, Estevane de Paula Pontes ${ }^{2}$

' Mestrando em Geografia do Programa de Pós-Graduação da Universidade Federal de Goiás/Regional Catalão e bolsista CAPES. Núcleo de Estudos e Pesquisas Socioambientais (Nepsa/CNPq).

2 Professora do Programa de Pós-graduação em Geografia, Universidade Federal de Goiás/RegionalCatalão. Núcleo de Estudos e Pesquisas Socioambientais (Nepsa/CNPq). * email:elvisley.rodrigues@gmail.com

\section{RESUMO}

A atividade canavieira está presente no território brasileiro desde a colonização até os dias atuais. O processo de territorialização do cultivo da cana-de-açúcar não foi homogêneo ao longo da história, e sim foi se apropriando e transformando algumas regiões de forma gradativa por meio de políticas de incentivo do governo federal. O presente trabalho busca compreender as transformações espaciais a partir da territorialização do setor sucroenergético no município de Frutal (MG), mais precisamente sobre a modernização da agricultura por meio do meio técnico científico. Para tanto, faz-se necessária a análise de algumas nuances, a saber: programas de incentivo como criação do Instituto do Açúcar 
e do Álcool (IAA); Proálcool; a crise do petróleo e o processo de expansão da lavoura canavieira pelas regiões do Brasil, com enfoque na Microrregião e no Município estudado. A pesquisa assentou-se em revisões bibliográficas acerca dos temas: processo de territorialização da cana-de-açúcar, modernização da agricultura, políticas e subsídios ofertados pelo Estado, bem como na expansão do agronegócio para o Cerrado.

Palavras-chave: Setor sucroenergético; Proálcool; IAA Frutal (MG) Inovação da Regional Catalão (2. : 2014 : Goiás) Coletânea Interdisciplinar em Pesquisa, Pós-Graduação e Inovação - Volume 1 : Estudos Ambientais, Território e Movimentos Sociais. Anais [livro eletrônico] / organizado por Adriana Freitas Neves, Idelvone Mendes Ferreira, Maria Helena de Paula, Petrus Henrique Ribeiro dos Anjos. São Paulo: Blucher, 2015. ISBN: 978-85-8039-109-1, DOI 10.5151/9788580391091-V1_Cap13 


\section{INTRODUC̣ÃO}

A busca por fontes de energia diversificadas propiciou, ao longo do século XX, importantes programas e subsídios de nível federal para suprir a demanda gerada pela crise do petróleo na década de 1970. O Brasil, desde seu período colonial, obteve por meio do cultivo da cana-de-açúcar, voltado para a produção de açúcar, importante fonte de renda. Esse setor, a princípio, territorializou-se na região nordeste do País e, por ser altamente rentável, expandiu-se para outros estados. Foi a partir da década de 1930, com a criação o Instituo de Açúcar e Álcool (IAA), que o governo passa a ter maior controle da produção de açúcar.

A crise do petróleo e a modernização da agricultura contribuíram significativamente com a expansão da atividade canavieira até a territorialização na Mesorregião do Triângulo Mineiro, com a intervenção estatal, com os subsídios e com a criação do Programa Nacional do Álcool (Proálcool), voltado para incentivar a produção de álcool, a fim de enfrentar a crise do petróleo. Assim, o cultivo da cana-de-açúcar ganha força e "novos” territórios.

A partir do início do século XXI, com o projeto de aumentar o consumo de álcool/etanol combustível, desenvolvem-se parcerias com a indústria automobilística, devido à produção de carros com motores flex, que funcionam a álcool e a gasolina, além do amento da mistura do álcool na gasolina, gerando, assim, a demanda de outras áreas a terem o cultivo de cana-de-açúcar. É nesse contexto que se insere o município de Frutal (MG), que, a partir do ano de 2005, recebe novos investimentos da agroindústria canavieira, a qual contribuirá para uma nova dinâmica econômica, espacial e demográfica.

Com isso, apresenta-se uma reflexão acerca das políticas públicas voltadas para a manutenção, expansão e perpetuação do setor sucroenergético, desde o período colonial e ao longo do século XX, sendo o Estado o principal financiador dessa atividade econômica, por meio de subsídios para a construção de novas agroindústrias sucroenergéticas, da construção de rodovias e do incentivo ao consumo do etanol. Assim, objetiva-se compreender quais foram os programas de incentivo e como estes contribuíram para a atividade canavieira territorializarse no Centro-Sul do Brasil, região de maior produção de açúcar e álcool do País. Pretende-se, também, analisar as transformações ocasionadas no município de Frutal (MG), por meio da territorialização do setor sucroenergético, a partir de meados da década de 2000. 


\section{POLÍTICAS DE REGULAC̣ÃO DA ECONOMIA CANAVIEIRA NO SÉCULO XX}

Desde o século XVI houve diferentes períodos e processos de reestruturação das políticas e ações do governo para o aprimoramento da atividade canavieira no Brasil. Para entender a formação da agroindústria sucroalcooleira, é preciso analisar as modificações estruturais do País em relação a este setor e à formação dos capitais de incentivo para o mesmo.

A implantação do cultivo canavieiro na região Nordeste, nos estados de Pernambuco e Bahia, durante o período colonial e ao longo dos séculos, quase não apresentou melhorias e avanços nas técnicas e no modo de produzir, permanecendo assim o atraso tecnológico na produção do açúcar. O trabalho utilizado era escravo, com bases no sistema patriarcal e com apenas uma variedade de cana-de-açúcar. É o que aponta Andrade (1994):

no período colonial foi mantido o sistema patriarcal e não houve grandes transformações tecnológicas, dominando, na agricultura, uma mesma variedade de cana, a crioula; do ponto de vista industrial, o banguê movido à água ou a tração animal - bois e éguas - produziria o açúcar mascavo para exportação. (ANDRADE, 1994, p. 18).

Ao longo dos séculos, a lavoura canavieira se manteve de forma quase que inalterada por ser uma atividade altamente rentável. Dessa forma, os senhores de engenho não revertiam parte dos lucros em modernização dos engenhos centrais. O cenário permaneceu inalterado até o produto brasileiro perder mercado para outros produtores de açúcar, como as Antilhas. Isso se deu por conta de uma crise oriunda do custo da produção e da má qualidade do produto (escuro), o que fez o governo financiar a implantação de modernas fábricas e engenhos centrais (ANDRADE, 1994).

No setor canavieiro, as pequenas fábricas não conseguiram resistir às variações da economia do mercado externo, vindo a fechar ou a se unir em associações com outros usineiros para disputar o mercado interno. Associada a essa crise financeira, enfrentada pela economia mundial, estava a falta de organização, de gerenciamento e planejamento dos proprietários e, também, a falta de manutenção e troca dos equipamentos. Nesse contexto, de acordo com Andrade (1994), 
a grande quantidade de fábricas de pequeno porte, a falta de estruturas modernas, a deterioração da maquinaria sem que houvesse uma competente substituição, além da queda constante dos preços do açúcar no mercado internacional e do mau gerenciamento dos empresários, foram fatores que levaram as pequenas usinas a crises constantes e, os usineiros, a se organizarem em associações regionais para disputar o mercado interno em crescimento (ANDRADE, 1994, p. 38).

O século XX é marcado por vários acontecimentos no cenário econômico, canavieiro e político do País. Nesse sentido, o governo brasileiro elaborou alguns programas voltados para o setor da agroindústria, em especial, ao canavieiro. Essa atividade sempre esteve ligada ao poder público e defendido por ele - o que ocorre desde o período colonial. Para Andrade (1994, p. 221), “[...] toda uma legislação protegia o senhor de engenho contra quem quer que pusesse em risco a sua atividade econômica, desde as classes ditas inferiores - indígenas e negros escravos - até os próprios credores, que não podiam executar os seus débitos".

A década de 1920 ficou caracterizada por uma crise econômica de escala global, a crise de 1929, provocada pela queda da bolsa de valores nos Estados Unidos da América (EUA). Tal crise foi sentida em vários países, principalmente, nos que tinham a maior parcela de sua economia voltada para a exportação de produtos primários. O Brasil foi um dos países atingidos. Nesse período, um dos principais produtos que o País exportava era o açúcar e, com a retração das exportações, foi ocasionado o aumento do estoque de açúcar nos engenhos.

Foi neste contexto que o governo federal adotou medidas intervencionistas. Uma das formas de regularizar o excedente de açúcar era direcionar a matériaprima usada na produção deste produto para outro produto. É a partir desse momento que o álcool anidro passará a ser produzido em larga escala, sendo comercializado no mercado brasileiro, como álcool carburante. O álcool, subproduto da cana, começou a ser comercializado a partir de 1920 como alternativa de maior rentabilidade e também como combustível; “[...] só nos anos 1930 é que passariam a produzir o álcool anidro.” (ANDRADE, 1994, p. 38). No ano de 1931, o governo federal promoveu incentivos à industrialização do álcool-motor, já que o álcool utilizado para o comércio era o hidratado.

Os dispositivos básicos do incentivo criado pelo governo para o consumo do álcool motor assim foram:

[...] o governo federal lançou o decreto $n^{\circ} 19.717$, de 20/02/1931, 
que estabelecia no geral os seguintes dispositivos básicos:

1. o importador de gasolina deveria adicionar à mesma $5 \%$ de álcool de procedência nacional;

2. nos automóveis de propriedades ou a serviço da União, dos Estados e dos Municípios, era obrigatório o consumo de combustível com pelo menos $10 \%$ de álcool;

3. até 31/03/1932, todo instrumental necessário a montagem de usinas para o fabrico e redestilação do álcool anidro estava isento de impostos e taxas de importação. (BRAY; FERREIRA; RUAS, 2000, p. 12).

No mesmo ano de 1932, o governo federal criou a Comissão de Defesa da Produção do Açúcar (CPDA), com o objetivo de orientar o setor canavieiro, pois, em razão dos reflexos da crise, era necessário conter a queda nos preços, organizar o excedente de açúcar produzido e, também, incentivar a produção de álcool motor. No entanto, a política da CPDA não gerou resultados significativos por conta da falta de estrutura e tecnologia. A queda nos preços continuou.

Em 1933, foi criado o Instituto do Álcool e Açúcar (IAA), que promoveria várias mudanças no setor canavieiro. O IAA foi criado "[...] com o objetivo de dirigir, intervir, fomentar e controlar a produção de açúcar e álcool do país.” (BRAY; FERREIRA; RUAS, 2000, p. 14). Esse órgão passou a estimular a modernização das áreas industriais do setor açucareiro.

A construção de destilarias e o subsídio na compra de maquinários para as usinas em funcionamento, objetivando a produção de álcool, foram políticas voltadas para combater a crise financeira em escala mundial, sentida também na agricultura brasileira, especialmente, no setor canavieiro. Tais medidas estatais foram adotadas para sanar a crise deste setor da economia e ter o controle da produção nacional, além de estabelecer cotas de produção para as empresas e usinas, limitando a instalação de novas fábricas (ANDRADE, 1994).

Como se pode observar, o século XX foi decisivo para a reestruturação do setor sucroalcooleiro no Brasil. Sendo as primeiras décadas marcadas por desajustes entre o mercado interno e mercado externo. Houve diversos acordos no cenário internacional que tentaram expandir as exportações do açúcar. Essas estratégias transformaram o setor canavieiro, devido à diversificação de produção e à modernização de técnicas e políticas econômicas que, de certa forma, deram novos rumos à atividade canavieira.

O incentivo à produção de álcool com programas do IAA ampliou a valorização do parque alcooleiro com a redução de oferta de petróleo causada com o período de guerra. É o que aponta Bray et al. (2000): 
Neste contexto ampliou-se a valorização do parque alcooleiro com a diminuição de derivados de petróleo no mercado nacional o álcool anidro carburante passou a ganhar, naquele momento, uma função de produto altamente estratégico para o País. (BRAY; FERREIRA; RUAS, 2000, p. 19).

O aumento do consumo de álcool, por meio de programas e incentivos do IAA, elevou para $20 \%$ o teor de mistura do álcool na gasolina em 1941, o que determinou a expansão do parque alcooleiro e da lavoura canavieira para áreas não tradicionais com o cultivo da lavoura canavieira na região CentroSul. Ampliou-se a tendência do deslocamento da hegemonia açucareira.

A década de 1950 caracterizou-se como a fase do crescimento e expansão da agroindústria canavieira no País mediante a demanda interna de álcool e açúcar. Agrega-se a essa nova dinâmica o processo de industrialização e urbanização do Brasil, bem como o processo de modernização da agricultura. $\mathrm{O}$ aumento do consumo interno levou os dirigentes do IAA a elevar a produção nacional. Já na década de 1960, o setor foi impulsionado pelo desenvolvimento da exportação de açúcar, ocasionado pela demanda de outros mercados internacionais, sobretudo, os Estados Unidos, que bloqueou o acordo comercial com Cuba, principal fornecedor de açúcar para o mercado Americano.

Por meio da política de regulação doIAA, oEstado consolida e (re)espacializa a lavoura canavieira no Centro-Sul, principalmente, em São Paulo, no Rio de Janeiro, no Paraná e em Minas Gerais. Esse processo se efetivou com a criação do Programa Nacional do Álcool (Proálcool), que contribuiu para a expansão da lavoura canavieira e modernizou os engenhos centrais, transformando-os em usinas sucroenergéticas, além do incentivo e das pesquisas voltadas para o aumento da produtividade via desenvolvimento de novas variedades de canade-açúcar, assunto discutido a seguir.

\section{PROÁlCOOL E EXPANSÃO CANAVIEIRA}

A intervenção do Estado brasileiro, subsidiando a agricultura por meio de programas, se fez presente desde o Brasil Colônia, doando terras via Capitanias Hereditárias, Sesmarias, Lei de Terras, até que no século XX, já com uma longa tradição na produção voltada para atender o mercado esterno, cria-se programas para aumentar a oferta de mercadorias, no caso o açúcar. Todavia, foi com o Proálcool que consolidou o projeto de expansão da lavoura canavieira para outros estados brasileiros. Vale ressaltar que esse 
período também foi marcado pela apropriação do Cerrado, utilizando-o para a produção agrícola.

Sendo assim, objetiva-se analisar as contribuições do Proálcool para a expansão da cana-de-açúcar no Centro-Sul do Brasil tornando essa região como maior polo produtor de açúcar e álcool. O uso de álcool como combustível surgiu como alternativa para a crise que o mercado açucareiro atravessou na década de 1970. Ocasionada pela baixa dos preços do açúcar no mercado internacional e também pela crise do petróleo, cujo preço do barril sofreu significativo aumento no preço. Por ser um produto de uso em escala mundial e muito consumido pelos países desenvolvidos, deflagrou-se a crise de abastecimento, inclusive no Brasil.

Para sanar o conflito no comércio do açúcar e no abastecimento de petróleo, o governo federal criou, no ano de 1975, o Proálcool, com o objetivo de aumentar a produção de álcool e, dessa forma, substituir a gasolina.

O PROÁLCOOL é um programa federal [...]. O seu objetivo foi de aumentar a produção de safras agro-energéticas e a capacidade industrial de transformação, visando à obtenção de álcool para a substituição da gasolina, assim incrementar o uso no setor químico. (BRAY; FERREIRA; RUAS, 2000, p. 55-56).

Com a crise na exportação de açúcar e um alto volume estocado, o que gerou prejuízos para a elite açucareira, o Estado viu-se obrigado a criar mecanismos para amenizar a situação e, assim, como já havia veículos automotores funcionando com o álcool associado com uma crise do petróleo, a saída foi incentivar a produção de álcool e de automóveis que utilizaria o produto como combustível. Dessa maneira, Thomaz Junior (2002) corrobora com o assunto abordado afirmando que,

o programa foi lançado e estrategicamente construído com o propósito de se produzir uma alternativa energética própria, contrapondo-se à dependência do petróleo, num período de ascensão dos preços internacionais do produto e de queda acentuada das cotações do açúcar. (THOMAZ JUNIOR, 2002, p. 76).

Para alcançar as demandas, foram dirigidos vários incentivos financeiros para o setor. E essa evolução se deu em três fases, sendo a primeira entre 1975 e 1979, a segunda entre 1980 e 1985 e a terceira de 1985 a 1990. 
A primeira etapa do Proálcool, iniciada entre 1975 a 1979, caracteriza-se a partir da utilização direta da cana para a produção do álcool, pois esse era um subproduto do açúcar. Foram destinados créditos subsidiados concedidos para a construção de destilarias anexas e autônomas no País, o que fomentou um crescimento na produção de álcool em virtude da ampliação instalada no sentido de atender à primeira etapa do programa (BRAY et al., 2000).

Outro choque do petróleo, em 1979, marcou a segunda etapa do Proálcool (1980 a 1985), período em que o governo federal manteve a política de liberação de créditos subsidiados voltada para atingir a meta de produção estipulada na fase anterior. Para conseguir o crédito, o governo fez exigências, como liberar créditos somente para construção de usinas com capacidade de produção superior a 60 mil litros diários, o que caracterizou a concentração de renda nas mãos de poucos empresários do açúcar, formando um monopólio capitalista açucareiro.

Com a prosperidade do Proálcool, houve o fortalecimento da indústria nacional voltada ao ramo açucareiro produzindo e fornecendo equipamentos para instalações de grande capacidade produtiva das novas destilarias autônomas instaladas, conforme aponta Bray et al. (2000). O estado de São Paulo foi privilegiado com as políticas do Proálcool, já que recebeu boa parte do capital investido, o que repercutiu na formação de um grande parque da agroindústria canavieira e na elevação da produção de açúcar e álcool, crescente desde a década de 1950. Houve ainda o fortalecimento dos novos estados produtores de álcool: Paraná, Mato Grosso do Sul, Minas Gerais, Goiás e Mato Grosso, formando assim, a hegemonia do setor no eixo Centro-Sul.

No período que compreende o terceiro momento do Proálcool (1985-1990) uma série de mudanças surgiu no aporte financeiro ofertado pelo programa caracterizado pelo corte dos financiamentos e subsídios para a instalação de novas usinas (THOMAZ JÚNIOR, 2002; BRAY,2000). Os cortes no orçamento, ofertado ao setor pelo Estado, atingiu o Instituto de Açúcar e Álcool (IAA), o que causou sua extinção em 1990, influenciando a indústria automobilística, já que a redução na oferta de álcool no mercado nacional causou desconfianças na indústria automobilística e ocasionou a queda na produção de automóveis movidos a álcool.

[...] com a crise de abastecimento no fim da década de 1980, o consumidor passou a desconfiar da capacidade do setor em suprir a demanda de álcool. Assim, houve uma grande queda na comercialização de veículos a álcool, face ao desinteresse da indústria automobilística na atualização dos modelos comercializados. (BRAY; FERREIRA; RUAS, 2000, p. 79). 
A inversão na produção do álcool para o açúcar que causou queda na oferta desse produto no mercado nacional deu-se pelo aumento na cotação dos preços do açúcar no mercado internacional, o que fez com que a canade-açúcar plantada fosse destinada para produzir açúcar. Sem a intervenção do IAA, o Estado deixou de controlar e mediar as ações do açúcar no cenário internacional, permitindo as próprias usinas a negociar e exportar diretamente sua produção (BRAY et al., 2000).

Em linhas gerais, o Proálcool foi um programa relevante para a economia brasileira. Foram medidas inovadoras em vários segmentos: oferta de crédito subsidiado para a expansão das áreas de lavoura canavieiras, para a implantação de novas destilarias de grande porte; colocação do álcool como alternativa de combustível nacional em face da crise do petróleo; incentivo estatal às indústrias automobilísticas para a produção de carros movidos a álcool; produção de equipamentos e máquinas voltadas para o setor de açúcar e álcool.

Em suma, foi um programa direcionado para os interesses públicos e privados e que contribuiu para a formação do capitalismo monopolista. Dessa forma, as ações do Estado, com a inserção de capital nacional, juntamente com capital privado e, também, internacional, foram responsáveis pela continuidade desse cultivo, de origem colonial, até os dias atuais.

As políticas direcionadas para a atividade canavieira ao longo do século XX contribuiu para o desenvolvimento técnico e instalação de fábricas mais eficientes construídas no estado de São Paulo, melhoramento das estradas construídas com dinheiro público, desenvolvimento em pesquisa de novas variedades de cana e avanços técnicos científicos na produção de adubos químicos e inseticidas, o que proporcionou o aumento da produção e expansão da lavoura canavieira.

É a partir dessa reflexão, acerca do papel do Estado como financiador da atividade canavieira no Brasil, que se objetiva compreender a dinâmica que o município de Frutal (MG) apresenta, desde a década de 1990, para a territorialização do setor sucroenergético, a partir do ano 2007, e como os desdobramentos sociais, espaciais, econômicos e territoriais tornaram-se mais visíveis, conforme é apresentado na próxima seção. 


\section{O SETOR SUCROENERGÉTICO E OS DESDOBRAMENTOS SOCIOESPACIAIS EM FRUTAL (MG)}

Com a difusão do Proálcool, a atividade econômica açucareira passa a exercer papel de relevada importância na economia brasileira. A partir da década de 1990, Minas Gerais, figura-se entre os maiores produtores de açúcar e álcool do País. A maior concentração da lavoura canavieira está localizada nas mesorregiões do Triângulo Mineiro/Alto Paranaíba e Sul/Sudeste de Minas, sendo estas, atualmente, as principais regiões produtoras de cana-de-açúcar do Estado mineiro.

O município de Frutal (MG) localiza-se na Mesorregião do Triângulo Mineiro, sendo sede da sua Microrregião de mesmo nome. O Município faz divisa com o estado de São Paulo, importante centro econômico e comercial, exercendo influência na Microrregião devido à sua proximidade dos centros mais desenvolvidos, como São José do Rio Preto (SP), que dista a $120 \mathrm{~km}$. Os municípios mineiros mais desenvolvidos e próximos de Frutal (MG) são: Uberaba (MG), a 140km, e Uberlândia (MG), a 170km; sendo o Município dotado de importantes rodovias federais, como as BRs 153 e 364, contribuindo, assim, para o desenvolvimento econômico.

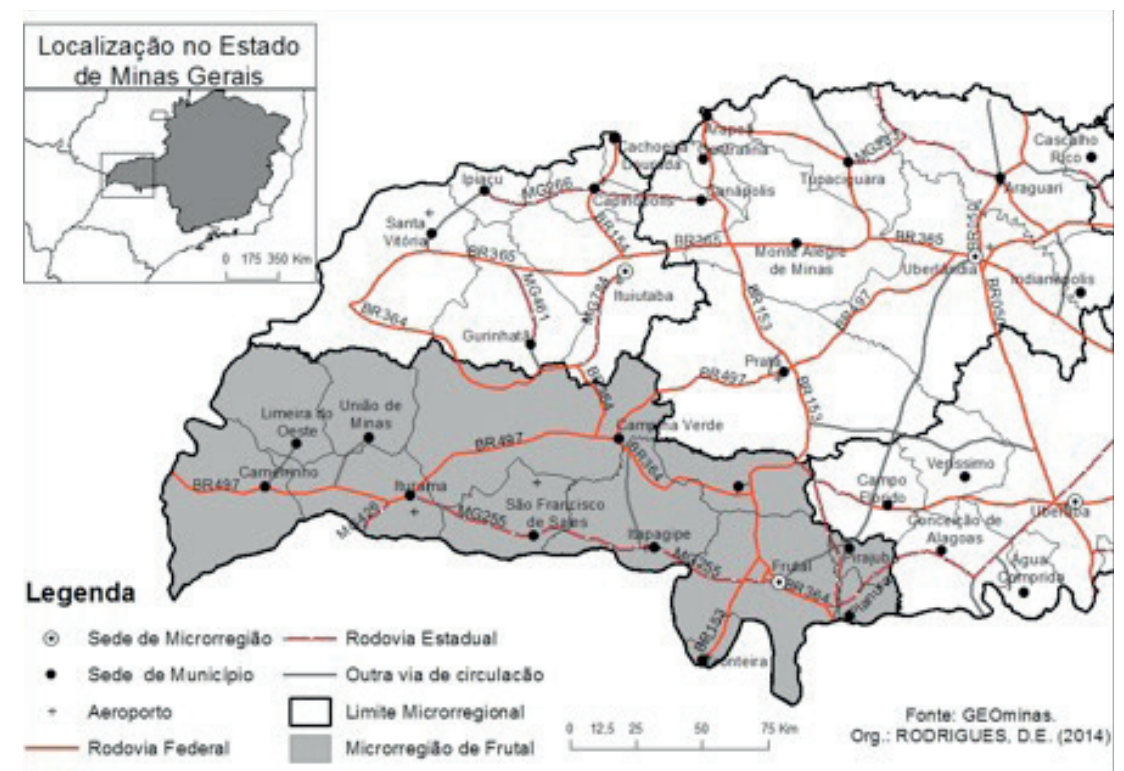

Mapa 1- Rodovias na Mesorregião do Triângulo Mineiro Alto Paranaíba: 2014. Fonte: COMPANHIA DE GEOPROCESSAMENTO DO ESTADO DE MINAS GERAIS - GEOMINAS, (2014). Cartografia: Rodrigues, D. E. (2014). 
A presença da agricultura como atividade econômica, faz-se presente no município de Frutal (MG) desde sua formação espacial, ocorrida no início do século XIX, o que assegurava o abastecimento dos viajantes que transitavam pela localidade em busca das regiões de explorações aurífera. Contribuindo, assim, para impulsionar seu crescimento demográfico.

As características geográficas são especificidades que não se repetem em outro ambiente de modo idêntico, por isso a importância de evidenciar a Geografia do Município, cujos fatores, como os elementos naturais, interferem e contribuem para a territorialização do setor sucroenergético em meados da primeira década do século XXI.

. O Município apresenta uma topografia composta por relevo plano com suaves ondulações, sobreposto ao domínio morfoclimático do Cerrado. Sua geomorfologia integra o planalto da Bacia Sedimentar do Paraná. Originam-se desta estrutura os solos conhecidos como latossolos, que predominam os tipos, latossolo vermelho-escuro e o latossolo vermelho-amarelo, distinguindo-se pela quantidade de ferro em sua composição, além da presença do latossolo roxo.

As propícias propriedades físicas do solo ocorrem em frações onde o relevo é favorável a mecanização da colheita da cana-de-açúcar. O clima do Município predominante é o Tropical, resultando em duas estações bem definidas, sendo o inverno seco e a verão chuvoso com temperatura média anual de $25,0^{\circ} \mathrm{C}$.

As características econômicas do Município, desde a sua gênese, definem-se pelas atividades agropecuárias; a criação de gado leiteiro e a produção de alguns gêneros alimentícios para a subsistência, como o cultivo de arroz, feijão, milho, cana-de-açúcar (utilizada para a produção de rapadura e para a alimentação dos animais), olaria e produção de gêneros derivados do leite. A produção de leite foi umas das principais e mais significativas atividades econômicas de Frutal (MG), conforme mostra os dados da produção municipal.

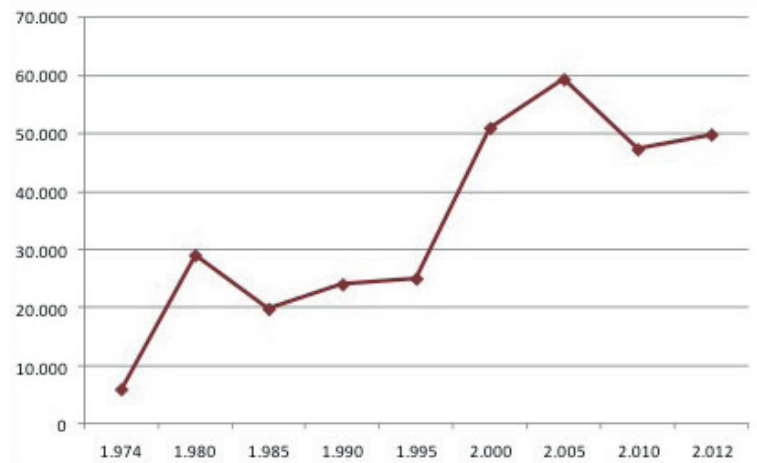

Gráfico 1- Produção de leite (em mil litros) município de Frutal (MG) (1974 2012).

Fonte - Pesquisa Pecuária Municipal (IBGE, 2014). Org. Oliveira, E. R. (2014). 
Observa-se que a produção de leite no início da década de 1970 tem um volume de 5.936 litros, já na década de 1980 há um expressivo aumento, com um volume de 29.038, ou seja, um crescimento de quase 500\%. Houve algumas oscilações, mas o que predomina é o crescimento contínuo desde o ano de 1974 até o ano de 2012, sendo o volume da produção neste período de 49.850 litros de leite, um crescimento aproximadamente dez vezes referente ao volume inicial.

Interessante destacar que a produção de leite mantinha seu desenvolvimento contínuo desde o ano de 1974 com grandes volumes produzidos, mas no período de 2005 a 2012, houve uma redução de mais de 10 mil litros de leite, conforme apresenta a tabela 1 .

Tabela 1 - Município de Frutal (MG): produção de leite (2005-2012).

\begin{tabular}{ccc}
\hline \multicolumn{4}{c}{ PRODUÇ̃̃O DE LEITE (MIL LITROS) } \\
\hline 2005 & 2010 & 2012 \\
\hline 59.364 & 47.319 & 49.850
\end{tabular}

Fonte - Pesquisa Pecuária Municipal (IBGE, 2014). Org.: Oliveira, E. R. (2014).

Cabe ressaltar que a tecnologia, como a ordenha mecanizada, contribui muito para o aumento da produtividade leiteira, juntamente com o melhoramento genético dos bovinos. Para produzir essa quantidade significativa de leite, o Município conta com um significativo rebanho de bovinos

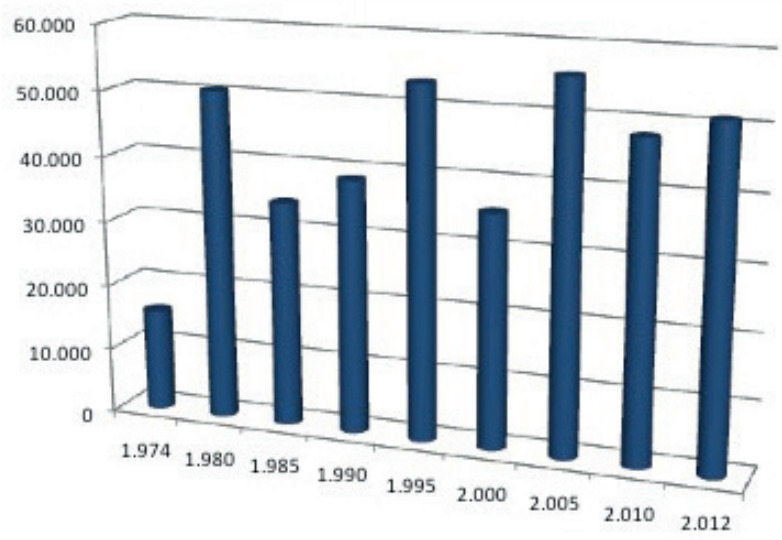

Gráfico 2- Município de Frutal (MG): vacas ordenhadas (1974-2012) Fonte - Pesquisa Pecuária Municipal (IBGE, 2014). Org.: Oliveira, E. R. (2014). 
Frutal (MG), além de manter a atividade leiteira, cultiva a tradição da criação de bovinos, atividade que também cresceu ao longo das décadas, como se pode constatar no gráfico 3 .

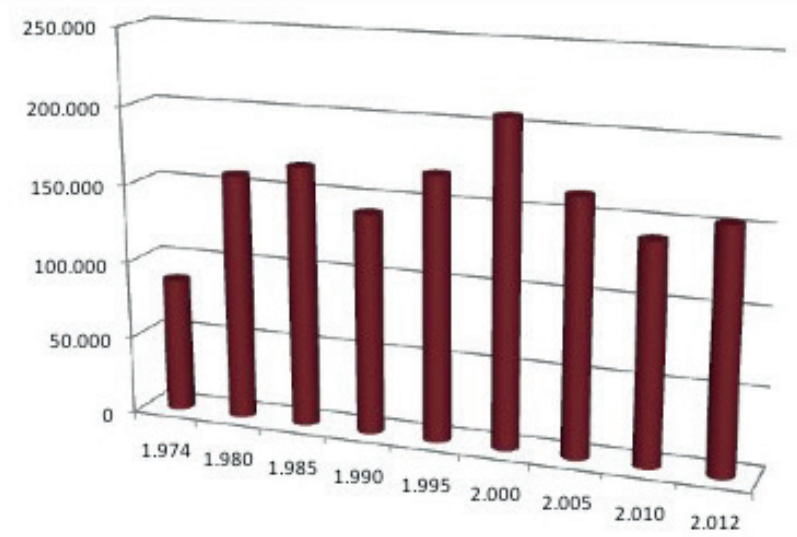

Gráfico 3 - Município de Frutal (MG): Rebanho de bovinos (1974-2012) Fonte - Pesquisa Pecuária Municipal (IBGE, 2014). Org. Oliveira, E. R. (2014).

A permanência da pecuária no Município está associada à outra atividade ligada à comercialização de gados: os leilões de gado. Frutal (MG) conta com 04 estabelecimentos destinados a realizações de eventos agropecuários, sendo eles o Leiloboi, situado no trevo do anel viário no entroncamento da BR-364; o Trevo Leilões, situado no trevo do entroncamento do anel viário com a MG255; a Cruzeta Leilões, situado no cruzamento da MG-255 com a BR-153 e o Boi de Ouro Leilões no perímetro urbano, na Avenida Presidente Juscelino Kubtschek (JK).

Dessa forma, o Município, no século XXI, exerce atividades econômicas que estão presentes desde a sua gênese. Cabe destacar que a atividade leiteira, mesmo havendo queda em sua produção, ainda é significativa no volume de produção. Lavouras como soja, milho, abacaxi, laranja, manga, borracha (látex coagulado) e cana-de-açúcar são permanentes e temporárias que complementam a economia do Município. 
Quadro 1- Produção agrícola de Frutal (MG), área collida em ha (1990-2012).

\begin{tabular}{|c|c|c|c|c|c|c|}
\hline \multirow{2}{*}{$\begin{array}{l}\text { PRODUTOS } \\
\text { AGRÍCOLAS }\end{array}$} & \multicolumn{6}{|c|}{ ÁREA PLANTADA (HECTARES) } \\
\hline & 1990 & 1995 & 2000 & 2005 & 2010 & 2012 \\
\hline ARROZ & 955 & 440 & 400 & 33 & 100 & 100 \\
\hline ABACAXI & 1.794 & 5.087 & 4.200 & 1.600 & 1.900 & 2.100 \\
\hline AMENDOIM & 2.045 & 40 & 50 & 1.500 & 450 & 500 \\
\hline FEIJÃO & 1.820 & 1.860 & 2.400 & 2.400 & - & - \\
\hline CANA-DE-AC̣ÚCAR & 1.900 & 3.750 & 3.600 & 8.228 & 30.689 & 49.000 \\
\hline LARANJA & 6.469 & 7.438 & 3.000 & 6.500 & 6.500 & 8.100 \\
\hline LÁTEX & - & 22 & 710 & 728 & 850 & - \\
\hline MANDIOCA & 160 & - & 50 & - & - & - \\
\hline MANGA & - & 113 & 37 & - & 141 & 170 \\
\hline MILHO & 6.236 & 3.500 & 5.980 & 3.000 & 3.000 & 4.500 \\
\hline SOJA & 9.970 & 9.000 & 12.500 & 30.000 & 9.000 & 10.000 \\
\hline SORGO & - & 200 & 3.260 & 3.800 & 400 & 1.900 \\
\hline ÁREA TOTAL (HA) & 28.819 & 29.817 & 34.021 & 54.389 & 52.278 & 77.280 \\
\hline
\end{tabular}

Fonte - Produç̃̃o Agrícola Municipal (IBGE, 2014). Org.: Oliveira, E. R., (2014).

Nota-se que alguns cultivos como arroz, amendoim, feijão, látex, mandioca e milho diminuíram o tamanho da área cultivada e outros deixaram de ser plantados, como é o caso do feijão, da mandioca e do látex. Enquanto o cultivo de soja, a partir do ano de 2005, reduziu de área plantada, a cana-de-açúcar deu um salto no crescimento da área cultivada, para entender o que ocorrera nesse período, basta observara queda no cultivo da soja e crescimento na área cultivada com cana-de-açúcar. Sendo assim, pode-se associar a redução da área 
cultivada de soja de $300 \%$ originada na crise que o setor enfrentou no ano de 2005 com a Ferrugem Asiática.

Esse fenômeno se repete em outros municípios da MRG de Frutal (MG), dentro da Mesorregião do Triângulo Mineiro/Alto Paranaíba, no estado de Minas Gerais e também em outros municípios de estados vizinhos como é o caso de Goiatuba (GO), região onde houve redução no tamanho da área plantada pela soja a partir do ano de 2004/2005. Nesse mesmo período, houve um crescimento da área cultivada pela cana-de-açúcar, ocorrendo assim a substituição de cultivos, de acordo com Costa (2013). Dessa forma, nota-se que a economia do Município está inserida dentro de uma lógica global, e que o mercado se adapta as exigências externas, ou seja, o que o mercado externo necessita.

O abacaxi e a laranja foram relevantes na formação socioeconômica da cidade, com uma significativa oferta de empregos, o que contribuiu para o desenvolvimento do Município. Observa-se que desde a década de 1990 há uma expansão da área cultivada no Município o que consequentemente contribui para o crescimento demográfico de Frutal (MG), sendo que a colheita de laranja e abacaxi demanda por mão de obra e isso contribui para que haja oferta de empregos em Frutal (MG), tanto nas lavouras quanto no comércio local.

Na segunda metade do século XX, Frutal $(\mathrm{MG})$ somava uma população de 30.737 na década de 1970; em 1980, 34.273; em 1990, 41.424; em 2000, 46.566; e no último censo, em 2010, 53.466 e para o ano de 2014 a população estimada é de 57.269 (IBGE, 2014), conforme o Gráfico 4.

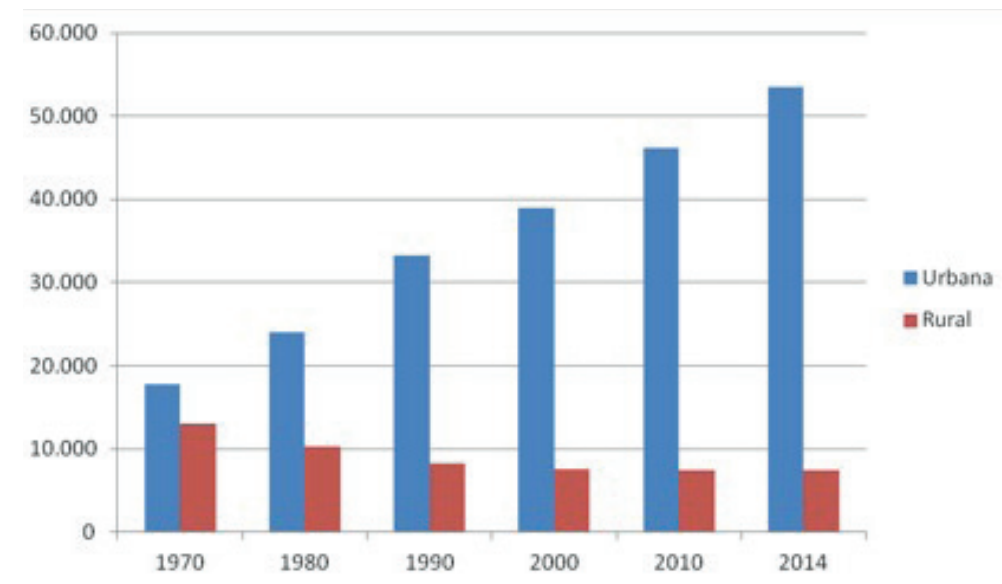

Gráfico 4 - Evolução demográfica do Município de Frutal (MG), urbana e rural (1997-2014).

Fonte: IBGE, Censo Demográíico 2014 Org. Oliveira, E. R. (2014). 
Outra atividade que tem contribuído com o crescimento econômico de Frutal (MG) é o cultivo da cana-de-açúcar que, a partir de 1990, vem aumentando gradativamente o tamanho da área cultivada. A partir de meados da primeira década do século XXI, o Município recebeu a implantação de duas usinas sucroenergéticas, sendo elas: a Usina Frutal, instalada em 2006, com início das atividades no ano seguinte e que fora adquirida pelo grupo Bunge; e a Usina Cerradão, do Grupo Queiroz de Queiroz e da Usina Moema S.A, instalada em 2007 e que iniciou as atividades em 2009. Juntas, essas usinas empregam cerca de 2.500 colaboradores, dos quais $70 \%$ são residentes no Município (SILVA, 2012).

As atividades relacionadas ao campo contribuem decisivamente para o desenvolvimento do comércio e da prestação de serviço local. Sabe-se que, com a territorialização do setor sucroenergético, outros setores econômicos ligados a essas atividades se instalaram no Município para atender à demanda originada por esse segmento.

O que se observa é que em Frutal (MG) tem ocorrido um crescimento econômico e social desde a década de 1990, mas foi a partir do ano 2006 que houve uma nova dinâmica econômica que provocou mudanças em todos os setores: habitação, educacional, instalação de indústrias e o fomento do segmento de prestação de serviços em geral. O Município recebeu duas universidades, sendo uma Estadual, o campus da Universidade do estado de Minas Gerais (UEMG), tendo os seguintes cursos de ensino superior ofertados: Administração, Comunicação Social, Direito, Geografia, Sistemas de Informação, Tecnologia em Alimentos e Tecnologia em Produção Sucroalcooleira; e a Faculdade Frutal (FAF) com os seguintes cursos ofertados, Administração, Nutrição, Pedagogia e Serviço Social o que também contribuiu para o crescimento e desenvolvimento econômico, social e espacial do Município, sendo que Frutal (MG) exerce dentro de sua Microrregião referência comercial e educacional.

\section{CONSIDERAC̣ÕES FINAIS}

Diante dos apontamentos referentes à atividade econômica da cana-de-açúcar, cabe ressaltar que, desde o Brasil Colônia, a ação do Estado se faz presente na instalação, na expansão e na manutenção, garantindo a perpetuação do setor canavieiro na economia brasileira.

Ao longo do século XX, observa-se que, em função da crise na oferta de petróleo, os países dependentes desta fonte de energia buscaram alternativas ante ao cenário daquele período. Assim, por meio de pesquisas desenvolvidas 
desde a década de 1920 e dos programas criados como o IAA e o Proálcool, o Brasil obtém uma fonte alternativa de combustível, ou seja, o álcool fabricado da cana-de-açúcar, reduzindo, desse modo, a dependência de petróleo.

Por meio de subsídios do governo brasileiro e dos programas voltados para esse setor da economia, a atividade canavieira expande-se por várias Unidades da Federação, promovendo, conjuntamente, transformações espaciais nos municípios onde a lavoura canavieira instalava-se. É nessa perspectiva que se insere o município de Frutal no Triângulo Mineiro que, a partir de meados da década de 2000, passa a sofrer alterações em suas estruturas econômica, espacial e social.

Acredita-se que um dos motivos dessa nova dinâmica, presente no Município, relaciona-se à territorialização do setor sucroenergético, uma vez que, no referido período, houve outros empreendimentos, por exemplo, a instalação de duas universidades. 


\section{Title: SUGAR-ENERGETIC SECTOR AND SPATIAL TRANSFORMATIONS IN FRUTAL (MG)}

\section{Abstract}

The sugarcane industry has been present in Brazil since colonization to the present day. The process of territorialization of the cultivation of cane sugar was not homogeneous throughout history, was appropriating and transforming some areas gradually through political incentives from the federal government. This paper seeks to understand the spatial transformations from the territorialization of the sugarcane industry in the municipality of Frutal (MG), from the modernization of agriculture through scientific technical means. For this it is necessary to analyze some nuances such as creating incentive programs like the Institute of Sugar and Alcohol (IAA), Proálcool, the oil crisis, and the process of expansion of sugarcane production by regions of Brazil, with focus on micro-region and the Municipality of study. The research was based on literature reviews on the topics, process of territorialization of cane sugar, modernization of agriculture, policies and subsidies offered by the state and the expansion of agribusiness for the Cerrado.

Keywords: Sugarcane industry; Proálcool; IAA; Frutal (MG). 


\section{REFERÊNCIAS}

ALVES-MAZZOTTI, A. J.; GEWANDSZNAJDER, F. 0 planejamento de pesquisas qualitativas. In: 0 método nas ciências naturais e sociais: pesquisa quantitativa e qualitativa. 2. Ed. São Paulo: Pioneira Thomson Learnig, 2002. p. 147-176.

ANDRADE, M. C, de. Modernização e pobreza: a expansão da agroindústria canavieira e seu impacto ecológico e social. São Paulo. Editora da Universidade Estadual Paulista, 1994.

BRAY, S. C.; FERREIRA, E. R.; RUAS, D. G. G. As políticas da agroindústria canavieira e o PROÁLCOOL no Brasil. Marília: UNESP, 2000. 104p.

BUNDE, A. Os impactos do agronegócio dos agrocombustíveis sobre o campesinato em Goiás. 2011. 208f. Dissertação (Mestrado) - Universidade Federal de Goiás, Campus Catalão, UFG. Catalão, 2011.

CASTRO, I. E; GOMES, P. C.; CORREAA, R. L. (Org.). Geografia, conceito e temas. Rio de Janeiro: Bertrand Brasil, 1995.

COSTA, R. H, da. 0 mito da desterritorialização: do "fim dos territórios" à multiterritorialidade. Rio de Janeiro. Bertrand Brasil, 2012.

FERLINI, V. L. A. A civilização do açúcar, séculos XVI a XVIII. Brasiliense, São Paulo, 1992, 8. ed. 96 p.

FURTADO, C. Formação econômica do Brasil. 27. ed. Cia Editora Nacional. São Paulo, 1998

INSTITUTO BRASILEIRO DE GEOGRAFIA E ESTATÍSTICA. Censo 2010. Disponível em: <http://www. ibge.gov.br/cidadesat/link.php? codigo=312710>. Acesso em: 15 jun. 2013.

LOURENC, O, L. A. B. A oeste das minas: escravos, índios e homens livres numa fronteira oitocentista, Triângulo Mineiro (1750 - 1861). Uberlândia. EDUFU, 2005. 358 p.

MOREIRA, R. Pensar e ser em geografia: ensaios de história, epistemologia e ontologia do espaço geográfico. São Paulo. Contexto. 2007.

PAULA, A. F. Desbravadores do Carmo de Fructal. Uberaba, MG. 2004. 592 p.

RANGEL, I. Questão agrária, industrialização e crise urbana no Brasil. Porto Alegre: Editora da UFRGS, 2004.

SANTOS, J. C. Dos canaviais à "Etanolatria": 0 (re)ordenamento do capital e do trabalho no setor sucroalcooleiro da Microrregião Geográfica de Presidente Prudente - SP. 2009. 375 f.: II. Tese (Doutorado em Geografia) Universidade Federal de Uberlândia, UFU. Uberlândia 2009.

SANTOS, M. A natureza do espaço: técnica e tempo, razão e emoç̃̃o. $4^{a}$ ed. $2^{a}$ reimpressão. São Paulo: Editora da Universidade de São Paulo, 2006.

Metamorfose do espaço habitado. São Paulo: Hucitec, 1988.

O Brasil: território e sociedade no início do século XX. Rio de Janeiro:

Record, 2003.

SILVA, A. R. P. As transformações socioespaciais de Frutal - MG. 2012, 172 f. il, Dissertação de mestrado em Geografia. Universidade Federal de Uberlândia, 2012.

SILVA, W. F. 0 avanço do setor sucroenergético no Cerrado: os impactos da expansão 
canavieira na dinâmica socioespacial de Jataí G0, 201 1, 21 8f. il, Dissertação de mestrado em Geografia. Universidade Federal de Goiás- Campus Jataí, 2011.

SOUZA, A. G. A territorialização do agronegócio canavieiro em Frutal - MG. 2012, 186, f. il, Dissertação de Mestrado em Geografia, Universidade Federal de Uberlândia, Uberlândia, 2012. THOMAZ JUNIOR, A. Por trás dos canaviais, os "nós" da cana: a relação capital $x$ trabalho e o movimento sindical dos trabalhadores na agroindústria canavieira paulista. São Paulo: Annablume/ Fapesp, 2002. $388 \mathrm{p}$. 
Seminário de Pesquisa, Pós-Graduacãoo e Inovação da Regional Catalão 